\title{
Validation of Mini Nutritional Assessment Scale in peritoneal dialysis patients
}

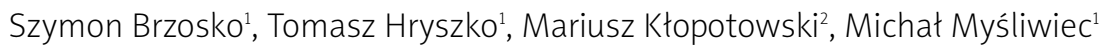

1Department of Nephrology and Transplantation with Dialysis Unit, Bialystok Medical University, Poland

2Department of Cardiology and Interventional Angiology, Cardiology Institute, Warsaw, Poland

Submitted: 21 November 2011

Accepted: 27 February 2012

Arch Med Sci 2013; 9, 4: 669-676

DOI: 10.5114/aoms.2012.31386

Copyright $\odot 2013$ Termedia \& Banach

\begin{abstract}
Introduction: Malnutrition is a negative predictive factor for survival in end stage renal disease (ESRD) patients. Coincidence of malnutrition, inflammation and atherosclerosis (MIA syndrome) in the dialysis population is an exceptionally poor outcome event. Due to flexibility, ease of performance and reproducibility, clinical scales are of particular value in assessment of nutritional status in ESRD patients. The aim of the present study was to evaluate the clinical value of Mini Nutritional Assessment (MNA) in peritoneal dialysis (PD) patients.

Material and methods: Nutritional status was assessed in 41 peritoneal dialysis patients by means of the MNA scale and malnutrition inflammation score (MIS). Some other clinical and laboratory parameters associated with nutritional status were analyzed. Patients were followed up for 30 months.

Results: In the analyzed group of patients a good nutritional state was diagnosed in 22 patients (54\%), risk of malnutrition in 17 (41\%) and malnutrition in 2 patients (5\%) based on the MNA scale. A strong correlation between MNA based nutritional status and MIS was found $(r=-0.85, p<0.01$, ANOVA, $p<0.01)$. Differences in time on dialysis, body mass index, concentration of albumin, cholesterol and triglycerides were noted between at risk/malnourished and well-nourished (according to MNA) patients. Statistically significant factors determining survival of patients by Cox proportional hazard analysis were age (HR 1.07), being at risk/malnourished according to MNA (HR 5.7), MIS (HR 1.2), and albumin (HR 0.13).

Conclusions: The MNA scale is a valuable, clinically suitable tool for assessment of nutritional status in peritoneal dialysis patients. Risk of malnutrition and malnutrition diagnosed by MNA identifies patients at high mortality risk.
\end{abstract}

Key words: malnutrition, peritoneal dialysis, mortality, Mini Nutritional Assessment.

\section{Introduction}

Protein-energy malnutrition is a negative predictor of survival in end stage renal disease patients. Its prevalence varies from $18 \%$ to $76 \%$ in the dialysis population $[1,2]$. Coincidence of malnutrition, inflammatory state and atherosclerosis, called MIA syndrome, in these patients predicts poor outcome [3-5]. Comprehensive clinical examination, and anthropometric and pertinent biochemical parameters are used for assessment of nutritional status of patients. Due to flexibility, ease of performance and reproducibility clinical scales are of particular value in assessment of nutritio-
Corresponding author: Szymon Brzosko MD, PhD Department of Nephrology and Transplantation with Dialysis Unit Bialystok Medical University 14 Zurawia St 15-540 Bialystok, Poland Phone: +48 857409458 E-mail: brzosko@mp.pl 
nal status in chronically ill patients. The subjective global assessment (SGA) scale is one of those widely used in end stage renal disease (ESRD) patients [6]. Its modification, the so-called Malnutrition-Inflammation Score (MIS), has been proposed to be an even more useful tool for this purpose [7]. The MIS system incorporates seven SGA components and additionally body mass index (BMI), together with serum albumin level and total iron-binding capacity (TIBC), as surrogate markers of systemic inflammation.

The Mini Nutritional Assessment (MNA) scale has been developed and designated to provide a fast, simple assessment of nutritional status of elderly people in clinics, hospitals and nursing homes $[8,9]$. It is used for rapid identification of subjects at risk of malnutrition and malnourished, to apply nutritional intervention. The tool evaluates the subject's nutritional status in 18 questions in four areas (basic anthropometrics, dietary intake, global indicators and self-assessed health status).

The aim of the present study (cohort, observational) was to evaluate the clinical value of MNA in peritoneal dialysis patients. This scale has been successfully used in the geriatric population to predict clinical complications due to malnutrition. Because of the wide range of co-morbidities among dialysis patients and the growing number of older ones, and on the other hand the ease of MNA application, we aimed to validate this scale in a population of peritoneal dialysis patients.

\section{Material and methods}

Nutritional status was assessed in 41 prevalent peritoneal dialysis patients ( $55 \pm 11$ years old, $723 \pm 623$ days on dialysis, 21 males) by means of the MNA scale and MIS. All patients recruited to the study were in

Table I. Composition of Mini Nutritional Assessment scale

\begin{tabular}{|c|c|}
\hline \multicolumn{2}{|r|}{ Mini Nutritional Assessment, 18 questions } \\
\hline & $\begin{array}{l}\text { Has food intake declined over the past } 3 \text { months due } \\
\text { to loss of appetite, digestive problems, chewing } \\
\text { or swallowing difficulties? } \\
0=\text { severe decrease in food intake } \\
1=\text { moderate decrease in food intake } \\
2=\text { no decrease in food intake }\end{array}$ \\
\hline & $\begin{array}{l}\text { Weight loss during the last } 3 \text { months } \\
0=\text { weight loss greater than } 3 \mathrm{~kg} \\
1=\text { does not know } \\
2=\text { weight loss between } 1 \text { and } 3 \mathrm{~kg} \\
3=\text { no weight loss }\end{array}$ \\
\hline & $\begin{array}{l}\text { Mobility } \\
0=\text { bed or chair bound } \\
1 \text { = able to get out of bed/chair but does not go out } \\
2 \text { = goes out }\end{array}$ \\
\hline & $\begin{array}{l}\text { Has the patient suffered psychological stress } \\
\text { or acute disease in the past } 3 \text { months? } \\
0=\text { yes } 2=\text { no }\end{array}$ \\
\hline & $\begin{array}{l}\text { Neuropsychological problems } \\
0=\text { severe dementia or depression } \\
1=\text { mild dementia } \\
2=\text { no psychological problems }\end{array}$ \\
\hline & $\begin{array}{l}\text { Body mass index }(\mathrm{BMI}) \\
0=\mathrm{BMI} \text { less than } 19 \\
1=\mathrm{BMI} 19 \text { to less than } 21 \\
2=\mathrm{BMI} 21 \text { to less than } 23 \\
3=\mathrm{BMI} 23 \text { or greater }\end{array}$ \\
\hline & $\begin{array}{l}\text { Lives independently (not in nursing home or hospital) } \\
1=\text { yes, } 0=\text { no }\end{array}$ \\
\hline & $\begin{array}{l}\text { Takes more than } 3 \text { prescription drugs per day } \\
0=\text { yes, } 1=\text { no }\end{array}$ \\
\hline & $\begin{array}{l}\text { Pressure sores or skin ulcers } \\
0=\text { yes, } 1=\text { no }\end{array}$ \\
\hline & $\begin{array}{l}\text { How many full meals does the patient eat daily? } \\
\begin{array}{l}0=1 \text { meal } \\
1=2 \text { meals } \\
2=3 \text { meals }\end{array}\end{array}$ \\
\hline
\end{tabular}

Mini Nutritional Assessment, 18 questions

K. Selected consumption markers for protein intake

- At least one serving of dairy products (milk, cheese, yoghurt) per day

- Two or more servings of legumes or eggs per week

- Meat, fish or poultry every day

$0.0=$ if 0 or 1 yes

$0.5=$ if 2 yes

$1.0=$ if 3 yes

$L$ Consumes two or more servings of fruit or vegetables per day?

$0=$ no $1=$ yes

M. How much fluid (water, juice, coffee, tea, milk...)

is consumed per day?

$0.0=$ less than 3 cups

$0.5=3$ to 5 cups

$1.0=$ more than 5 cups

N. Mode of feeding

$0=$ unable to eat without assistance

$1=$ self-fed with some difficulty

2 = self-fed without any problem

O. Self view of nutritional status

$0=$ views self as being malnourished

$1=$ is uncertain of nutritional state

2 = views self as having no nutritional problem

P. In comparison with other people of the same age, how does the patient consider his/her health status?

$0.0=$ not as good

$0.5=$ does not know

$1.0=$ as good

$2.0=$ better

Q. Mid-arm circumference (MAC) in $\mathrm{cm}$

$0.0=$ MAC less than 21

$0.5=$ MAC 21 to 22

1.0 = MAC 22 or greater

R. Calf circumference (CC) in $\mathrm{cm}$

$0=C C$ less than 31

$1=$ CC 31 or greater 
the peritoneal dialysis program in the Department of Nephrology with Dialysis Unit (Medical University of Bialystok) and gave informed consent.

Exclusion criteria were: time on dialysis shorter than 30 days, acute illness during the preceding 30 days, end stage of disseminated neoplastic disease, and lack of consent to participate in the study. According to the exclusion criteria, 4 out of 45 prevalent patients who were in the peritoneal dialysis program were not enrolled in the study. Two of them refused participation, one was in a terminal clinical state, and one had just started the peritoneal dialysis program.

The MNA is composed of 18 items and includes anthropometric measurements, global assessment, a dietary questionnaire and subjective assessment (Table I). The maximum score is 30 points and the risk for malnutrition is associated with lower values. Classic cut-off values for grouping were used in the study (24-30 points - normal nutritional status; $17-23.5$ - at risk of malnutrition; below 17 - malnutrition).

The MIS assessment was performed according to the description by Kalantar-Zadeh et al. [7] It consisted of medical history (weight changes, dietary intake, gastrointestinal symptoms, functional capacity and presence of comorbidities), physical examination (loss of subcutaneous fat and muscle wasting) and laboratory parameters (serum albumin and total iron- binding capacity). Each of the components was scored from 0 (normal) to 3 (severely abnormal). The sum of all points gave the total MIS value (maximum 30).

Other clinical and laboratory parameters analyzed included: age, time on dialysis, presence of atherosclerotic cardiovascular or cerebrovascular disease (defined as history of coronary heart disease, myocardial infarction, or stroke; data collected by patient interview and chart review), diabetes mellitus (DM), arterial hypertension (data collected by patient interview/chart review and/or use of antihypertensive drugs), BMI, concentration of hemoglobin ( $\mathrm{Hb})$, iron (Fe), ferritin, urea, creatinine, albumin, fibrinogen (Fbg), total cholesterol (TC) and triglycerides (TG), glucose and C-reactive protein (CRP). All biochemistry measurements were performed by standard laboratory methods in the hospital central laboratory (Wojewodzki Szpital Specjalistyczny in Bialystok). CRP was assessed using a commercially available kit - Quantikine human CRP immunoassay test (R\&D systems). Atherosclerotic cardiovascular or cerebrovascular disease and/or DM were defined as comorbidities for statistical analysis. For the descriptive statistics inflammation was defined as CRP above $10 \mathrm{mg} / \mathrm{l}$, and hypoalbuminemia when the albumin level was below $3.5 \mathrm{mg} / \mathrm{dl}$.

Analysis of survival (30 months of follow-up) for the group was performed. The study was performed from June 2003 and all events were censored on January 2006. There was no loss to follow-up and 2 patients were transplanted.

\section{Statistical analysis}

Results of descriptive analysis are expressed as mean \pm SD and numbers (\%) unless otherwise specified. Student's $t$-test, Mann-Whitney $U$-test, analysis of variance (ANOVA) and $\chi^{2}$ test were used to compare variables, as appropriate. For the linear correlation of two variables Spearman's rank test or Pearson's test was applied. Univariate (crude) survival analysis was applied using standard Kaplan-Meier life tables and Cox proportional hazard regression models to determine predictors for patients' mortality. Selected multivariate models were also tested to adjust the influence of covariates potentially affecting survival. For that purpose, demographics, comorbidities and laboratory results adjusted models were created and tested. Results were expressed as hazard ratio (HR) and its 95\% confidence interval $(95 \% \mathrm{Cl})$. For the comparison of two scales as predictors for hypoalbuminemia, receiver operating characteristic (ROC) curves analysis was performed. Areas under the curve (AUC) were determined for the scales, and they were compared. Differences were regarded as statistically significant when $p<0.05$. Statistical analysis was performed with the package Statistica 6.0 (Stat Soft, Inc, Tulsa, USA).

\section{Results}

Clinical characteristics of the examined group of patients are shown in Table II. Risk of malnutrition was detected in $41 \%(n=17)$, and malnutrition in $5 \%(n=2)$ of patients as measured by MNA. As there were just two cases assessed as malnourished by MNA the group "at risk" and "malnourished" were joined for further statistical analysis (at risk/malnourished). Mean MIS was $6 \pm 4$ points (1-23), and a strong relation between the results of these two scales was observed $(r=-0.85, p<0.01$; ANOVA, $p<0.05$, Figure 1). A linear correlation between MNA score and albumin concentration was present $(r=0.42, p<0.05)$. Mean body weight of patients was $70 \pm 13 \mathrm{~kg}$ and BMI $25 \pm 4 \mathrm{~kg} / \mathrm{m}^{2}$. Only 4 patients (10\%) had BMI less than $20 \mathrm{~kg} / \mathrm{m}^{2}$ but hypoalbuminemia, defined as albumin concentration below $3.5 \mathrm{mg} / \mathrm{dl}$, was present in $25 \mathrm{pa}-$ tients (61\%). Patients who were classified as well nourished ( $n=22,54 \%$ ) when compared to at risk/malnourished ( $n=19,46 \%)$ according to MNA were characterized by shorter time on dialysis (530 \pm 371 days vs. $949 \pm 792$ days, $p<0.05$ ), and higher BMI $\left(26.2 \pm 4.2 \mathrm{~kg} / \mathrm{m}^{2}\right.$ vs. $\left.23.7 \pm 3.7 \mathrm{~kg} / \mathrm{m}^{2}, p<0.05\right)$, concentration of albumin $(3.6 \pm 0.3 \mathrm{~g} / \mathrm{dl}$ vs. $3.2 \pm 0.6$ $\mathrm{g} / \mathrm{dl}, p<0.01)$, TC $(226 \pm 39 \mathrm{mg} / \mathrm{dl}$ vs. $195 \pm 55 \mathrm{mg} / \mathrm{dl}$, $p=0.05)$ and TG $(192 \pm 85 \mathrm{mg} / \mathrm{dl}$ vs. $132 \pm 60 \mathrm{mg} / \mathrm{dl}$, $p<0.02$ ) (shown in Table III).

Both scales were similar in determination of hypoalbuminemia. In ROC curve analysis AUC for 
Table II. Basic clinical characteristics of patients

\begin{tabular}{|c|c|c|c|c|}
\hline Variable & Whole group & Well $(n=22)$ & At risk $(n=17)$ & Mal $(n=2)$ \\
\hline Age \pm SD [years] & $55 \pm 11$ & $55 \pm 11$ & $55 \pm 12$ & $60 \pm 6$ \\
\hline Males, $n[\%]$ & $21(50)$ & $9(41)$ & $11(65)$ & $1(50)$ \\
\hline \multicolumn{5}{|l|}{ Causes of ESRD, $n[\%]$} \\
\hline Diabetic nephropathy & $10(25)$ & $5(23)$ & $4(24)$ & $1(50)$ \\
\hline Glomerulonephritis & $11(26)$ & $4(18)$ & $7(41)$ & $0(0)$ \\
\hline Adult polycystic kidney disease & $7(17)$ & $5(23)$ & $2(12)$ & $0(0)$ \\
\hline Interstitial nephritis & $4(10)$ & $1(4)$ & $3(18)$ & $0(0)$ \\
\hline Hypertensive nephropathy & $3(7)$ & $2(9)$ & $0(0)$ & $1(50)$ \\
\hline Others & $6(15)$ & $5(23)$ & $1(5)$ & $0(0)$ \\
\hline Co-morbidities, $n[\%]$ & $19(46)$ & $11(50)$ & $7(41)$ & $1(50)$ \\
\hline Coronary heart disease & $12(29)$ & $8(36)$ & $4(24)$ & $0(0)$ \\
\hline Stroke & $4(10)$ & $2(9)$ & $2(12)$ & $0(0)$ \\
\hline Diabetes mellitus & $13(31)$ & $8(36)$ & $4(24)$ & $1(50)$ \\
\hline Arterial hypertension, $n[\%]$ & $37(90)$ & $20(91)$ & $15(88)$ & $2(100)$ \\
\hline Time on dialysis \pm SD (range) [days] & $\begin{array}{l}723 \pm 623 \\
(85-3300)\end{array}$ & $\begin{array}{c}530 \pm 371 \\
(85-1394)\end{array}$ & $\begin{array}{c}980 \pm 820 \\
(114-3030)\end{array}$ & $\begin{array}{c}675 \pm 599 \\
(251-1099)\end{array}$ \\
\hline
\end{tabular}

Well - well nourished according to MNA, At risk - at risk of malnutrition according to MNA, Mal - malnourished according to MNA, ESRD - end stage renal disease

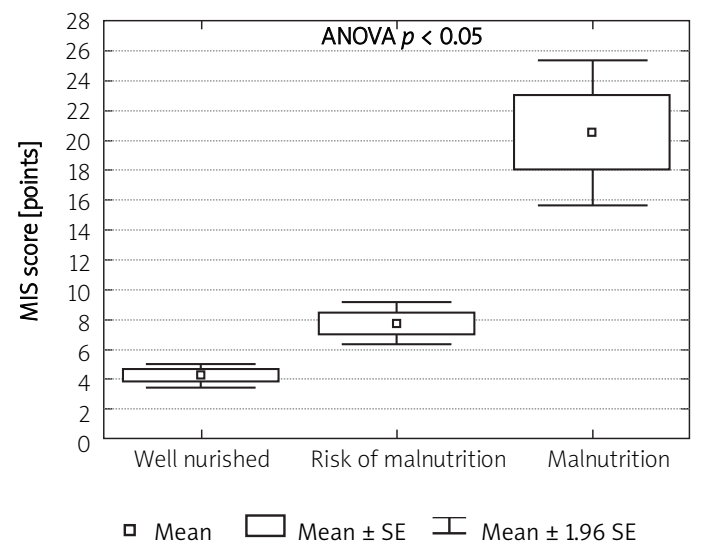

Figure 1. Association between MIS and nutritional status assessed by MNA (ANOVA $p<0.05)$

MNA was $0.75 \pm 0.07$ and for MIS was $0.78 \pm 0.07$ (Figure 2), which was comparable ( $p=N S$ ).

During 2.5 years of follow-up 8 patients (20\%) died, which gave the annual mortality of $8 \%$. Most of them were assessed as "at risk" or "malnourished" according to MNA (Figure 3, log rank test $p<0.05)$. Factors significantly influencing risk of mortality in simple models of Cox proportional hazard were being at risk/malnourished according to MNA (HR 5.7, 95\% Cl 4.1-7.2), MIS per 1 unit (HR 1.2, $95 \% \mathrm{Cl} 1.09-1.32)$, age per 1 year (HR $1.07,95 \% \mathrm{Cl}$ $1.01-1.14)$ and albumin per $1 \mathrm{~g} / \mathrm{dl}(\mathrm{HR} 0.13,95 \% \mathrm{Cl}$ 0.05-0.37). Results of particular crude and multiple regression models are summarized in Table IV. Being at risk/malnourished assessed by MNA and higher MIS values were both statistically significant factors influencing patients' survival even after adjustments for demographics, comorbidities and laboratory values. At risk/malnutrition according to MNA was below statistical significance only in the Cox regression model adjusted for albumin and age. In this case concentration of albumin was the strongest and only predictor for survival. When only "well-nourished" and "at risk of malnutrition" cases according to MNA were included in the Cox regression model the results were not statistically significant although a trend for increasing risk was evident (HR 4.48, 95\% Cl 0.9-12.2). It must be pointed out that both "malnourished" patients died during follow-up (complete observations), so excluding them from the regression weakened the calculated hazard.

\section{Discussion}

The results of this study prove the efficacy of the MNA scale for detecting malnutrition in peritoneal dialysis patients. Assessment of nutritional status was comparable to that obtained by MIS, which is a modification of the classic SGA scale (Figure 1). In the present study patients classified as at risk/malnourished by the MNA scale had much higher mortality risk during the follow-up period as revealed by applied survival analysis. The negative impact of malnutrition on survival was still observed after adjustments for basic demographics and comorbidities (Table IV). 
Table III. Clinical and laboratory characteristics of examined patients classified by MNA scale

\begin{tabular}{|c|c|c|c|c|}
\hline Parameter & Well $(n=22)$ & At risk $(n=17)$ & $\operatorname{Mal}(n=2)$ & Risk/Mal $(n=19)$ \\
\hline Age [years] & $55 \pm 12$ & $55 \pm 13$ & $60 \pm 6$ & $56 \pm 12$ \\
\hline Time on dialysis [days] ${ }^{\star}$ & $530 \pm 371$ & $981 \pm 820$ & $675 \pm 600$ & $949 \pm 792$ \\
\hline $\mathrm{BMI}\left[\mathrm{kg} / \mathrm{m}^{2}\right]^{\star}$ & $26.2 \pm 4.2$ & $24.0 \pm 3.7$ & $21.0 \pm 1.3$ & $23.7 \pm 3.7$ \\
\hline $\mathrm{Hb}[\mathrm{g} / \mathrm{dl}]$ & $12.6 \pm 1.1$ & $12.6 \pm 1.9$ & $12.0 \pm 3.1$ & $12.5 \pm 2.0$ \\
\hline $\mathrm{Fe}[\mu \mathrm{g} / \mathrm{dl}]$ & $68.9 \pm 28.5$ & $91.3 \pm 54.5$ & $63 \pm 21.9$ & $88.4 \pm 52.3$ \\
\hline $\mathrm{TIBC}[\mu \mathrm{g} / \mathrm{dl}]$ & $305.8 \pm 70.6$ & $305.6 \pm 82.7$ & $156.0 \pm 21.2$ & $289.0 \pm 91.7$ \\
\hline Ferritin $[\mathrm{ng} / \mathrm{ml}]$ & $206.0 \pm 128.7$ & $323.4 \pm 318.7$ & $524.0 \pm 579.8$ & $344.5 \pm 336.2$ \\
\hline Urea [mg/dl] & $106.6 \pm 25.0$ & $115.0 \pm 35.6$ & $51.7 \pm 16.2$ & $108.4 \pm 39.2$ \\
\hline Creatinine $[\mathrm{mg} / \mathrm{dl}]$ & $7.5 \pm 1.9$ & $8.6 \pm 2.8$ & $4.8 \pm 2.1$ & $8.3 \pm 2.9$ \\
\hline Albumin $[\mathrm{g} / \mathrm{dl}]^{\#}$ & $3.6 \pm 0.3$ & $3.4 \pm 0.3$ & $1.9 \pm 0.1$ & $3.2 \pm 0.6$ \\
\hline Hypoalbum. [\%] & 23 & 71 & 100 & 74 \\
\hline $\mathrm{Fbg}[\mathrm{mg} / \mathrm{dl}]$ & $459.7 \pm 67.5$ & $440.7 \pm 81.2$ & $292.5 \pm 44.4$ & $424.3 \pm 90.7$ \\
\hline $\mathrm{TC}[\mathrm{mg} / \mathrm{dl}]$ & $226 \pm 39$ & $200 \pm 55$ & $161 \pm 61$ & $195 \pm 55$ \\
\hline $\mathrm{TG}[\mathrm{mg} / \mathrm{dl}]^{*}$ & $192 \pm 85$ & $131 \pm 61$ & $142 \pm 76$ & $132 \pm 60$ \\
\hline Glucose $[\mathrm{mg} / \mathrm{dl}]$ & $125 \pm 39$ & $118 \pm 48$ & $186 \pm 112$ & $125 \pm 57$ \\
\hline $\mathrm{CRP}[\mathrm{mg} / \mathrm{l}]$ & $5.6 \pm 7.1$ & $9.7 \pm 13.1$ & $23.1 \pm 32.3$ & $11.2 \pm 15.2$ \\
\hline Inflammation [\%] & 18 & 29 & 50 & 32 \\
\hline Comorbidities [\%] & 50 & 41 & 50 & 42 \\
\hline $\mathrm{Kt} / \mathrm{V}$ & $2.2 \pm 0.5$ & $2.6 \pm 1.3$ & $2.1 \pm 0.9$ & $2.6 \pm 1.2$ \\
\hline nPCR [g/kg/day] & $1.5 \pm 0.4$ & $1.8 \pm 0.6$ & $1.0 \pm 0.5$ & $1.7 \pm 0.6$ \\
\hline
\end{tabular}

Well - well nourished according to MNA, At risk - at risk of malnutrition according to MNA, Mal - malnourished according to MNA, Risk/Mal at risk of malnutrition or malnourished, BMI - body mass index, $\mathrm{Hb}$ - haemoglobin, Fe - iron, TIBC - total iron binding capacity, Fbg - fibrinogen, TC - total cholesterol, TG - triglycerides, CRP-C-reactive protein, $n P C R$ - normalized protein catabolic rate, ${ }^{*} p<0.05$, ${ }^{\#} p<0.01$ for comparison of Well vs. Risk/Mal

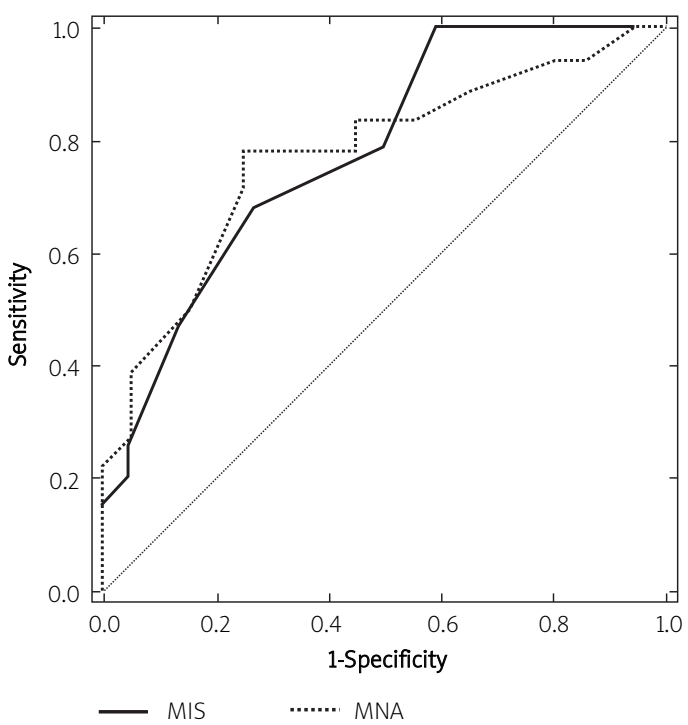

Figure 2. ROC curves for MNA and MIS scales as predictors of hypoalbuminemia ( $p=$ NS for comparison of the areas under the curves)

Protein energy wasting has been considered as an important and common negative predictor for mortality and morbidity in chronic renal disease

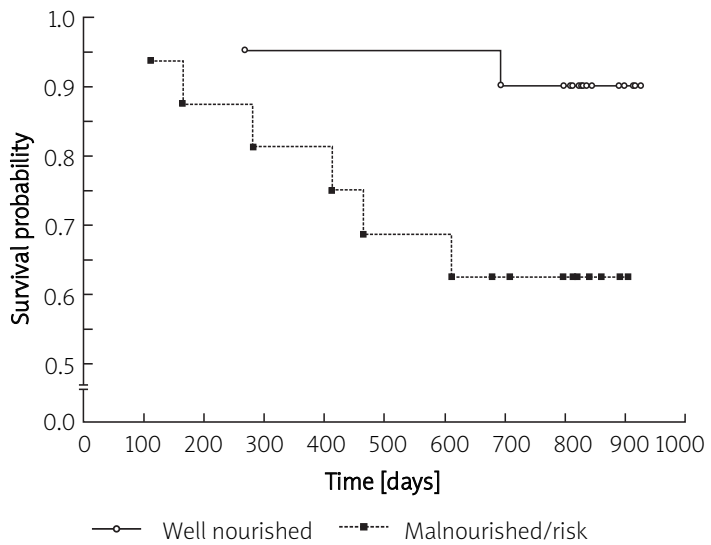

Figure 3. Kaplan-Meier cumulative survival curves for the two analyzed groups of patients (log-rank test, $p<0.05)$

patients including those on peritoneal dialysis [10]. Many comprehensive guidelines devoted to care of dialysis patients suggest nutritional counseling and screening for any signs of malnutrition as a routine clinical procedure. There is no universal method for assessment of nutritional status and many clinical, anthropometric, biochemical and more sophistica- 
Table IV. Cox proportional hazard regression analysis of variables influencing survival of patients

\begin{tabular}{|c|c|c|c|c|c|}
\hline & \multirow{2}{*}{$\begin{array}{l}\text { Crude model } \\
\text { HR }(95 \% \mathrm{Cl})\end{array}$} & \multirow{2}{*}{$\begin{array}{c}\begin{array}{c}\text { Demographics- } \\
\text { adjusted model }\end{array} \\
\text { HR }(95 \% \mathrm{Cl})\end{array}$} & \multirow{2}{*}{$\begin{array}{c}\begin{array}{c}\text { Comorbidities- } \\
\text { adjusted model }\end{array} \\
\text { HR }(95 \% \mathrm{Cl})\end{array}$} & \multicolumn{2}{|c|}{ Lab values-adjusted models } \\
\hline & & & & $\mathrm{HR}(95 \% \mathrm{Cl})$ & $\mathrm{HR}(95 \% \mathrm{Cl})$ \\
\hline MNA [at risk/mal] & $5.70(4.10-7.20)^{\star}$ & $6.13(4.53-7.74)^{\star}$ & $6.69(5.13-8.25)^{*}$ & $2.57(0.63-4.51)$ & $5.48(3.88-7.08)^{\star}$ \\
\hline MIS [unit] & $1.20(1.09-1.32)^{\#}$ & & & & \\
\hline Age [year] & $1.07(1.01-1.14)^{\star}$ & $1.08(1.01-1.16)^{\star}$ & $1.06(0.98-1.13)$ & $1.05(0.96-1.15)$ & $1.08(1.01-1.16)^{\star}$ \\
\hline Sex [male] & $1.52(0.36-6.39)$ & $1.10(0.27-4.51)$ & & & \\
\hline Albumin [g/dl] & $0.13(0.05-0.37)^{\#}$ & & & $0.23(0.07-0.76)^{*}$ & \\
\hline $\mathrm{TC}[\mathrm{mg} / \mathrm{dl}]$ & $0.98(0.97-1.01)$ & & & & 0.99 (0.98-1.01) \\
\hline $\mathrm{CRP}[\mathrm{mg} / \mathrm{l}]$ & $1.02(0.97-1.12)$ & & & & $1.01(0.96-1.06)$ \\
\hline Comorbidities (presence) & 3.05 (0.80-11.8) & & $2.34(0.53-10.31)$ & & \\
\hline MIS [per 1 unit] & & $1.19(1.05-1.34)^{\#}$ & $1.20(1.06-1.35)^{\#}$ & $1.19(1.06-1.34)^{\#}$ & $1.19(1.06-1.14)^{\#}$ \\
\hline Age [year] & & $1.05(0.97-1.14)$ & $1.05(0.97-1.13)$ & $1.07(0.99-1.15)$ & 1.07 (0.99-1.16) \\
\hline Sex [male] & & $1.22(0.28-5.22)$ & & & \\
\hline \multicolumn{6}{|l|}{ Albumin $[\mathrm{g} / \mathrm{dl}]$} \\
\hline $\mathrm{TC}[\mathrm{mg} / \mathrm{dl}]$ & & & & $0.99(0.97-1.01)$ & $0.99(0.97-1.01)$ \\
\hline $\mathrm{CRP}[\mathrm{mg} / \mathrm{l}]$ & & & & & $1.01(0.95-1.05)$ \\
\hline Comorbidities (presence) & & & $2.22(0.52-9.56)$ & & \\
\hline
\end{tabular}

Comorbidities - presence of atherosclerotic cardiovascular and/or cerebrovascular disease and/or diabetes mellitus

ted methods (bioelectrical impedance, dual energy X-ray absorptiometry, computed tomography) are in research use [11]. In light of these methodological obstacles it is suggested that several parameters should be considered together [12], but taking into account the availability and high costs of the mentioned methods it would not be cost effective and widely used. Clinical scales such as SGA, MIS and MNA are the answer to this problem. They are much simpler, but still acquire complex data and appear very useful for routine clinical use. SGA was successfully applied in the CANUSA study and was predictive for mortality in peritoneal dialysis patients [13].

The results of this study show a strong correlation between MNA scale and MIS. The latter scale is a modification of SGA taking into account elements of chronic inflammation (hypoalbuminemia and transferrin level), so common in dialysis patients, and often preceding malnutrition. The MNA scale is much simpler in use, needs no biochemical results and can be performed by non-specialized personnel, e.g. a nurse who has been introduced to the method. In contrast to MIS, in the MNA scale anthropometric data include direct measurements of calf and mid-arm circumference but not a subjective assessment of fat and muscle tissue status (which is the case in MIS and classic SGA) and can be somewhat subjective and observer-dependent. The two scales were comparative as predictors of hypoalbuminemia when assessed by ROC curve analysis. However, it should be appreciated that albumin level is part of the MIS system but not the MNA scale. This fact seems to make the latter tool even more valuable for nutritional assessment. It must be pointed out that concentration of albumin is not sensitive and not specific with regard to the diagnosis of protein-energy malnutrition although it is strongly associated with morbidity and mortality in this population. The increase in mortality with hypoalbuminemia appears to occur even at near normal albumin levels $(3.5 \mathrm{~g} / \mathrm{dl})$ in hemodialysis patients [14]. In the present study hypoalbuminemia was also a strong predictor for mortality as revealed by Cox proportional hazard analysis. Some patients treated with maintenance dialysis have a low plasma albumin concentration due to decreased albumin synthesis despite apparently adequate dialysis dose and protein intake $[15,16]$. These patients have evidence of an acute phase response, suggesting that an underlying inflammatory process (such as occult infections or inflammation) is responsible for the decline in albumin production. This group of patients may also develop malnutrition, which is not possible to correct solely by increased protein delivery or dialysis dose. This type of nutritional disorder is called type II malnutrition [17] and actually is a form of malnutrition inflammation syndrome. Neither MIS nor MNA is able to differentiate type I from type II malnutrition. The former was created with the intention to reveal patients with an inflammatory process being a culprit of potential alert symptoms reviewed by the 
classic SGA scale. Recently it has been shown that MIS is indeed a strong predictor for cardiovascular and infection events in peritoneal dialysis patients, and correlates with co-morbid conditions [18]. These results prove the coincidence of proinflammatory conditions and malnutrition as a fatal predictor for future events. On the other hand, one should bear in mind that peritoneal dialysis patients do have loss of albumins with dialysate and can have loss of appetite (due to continuous calories delivery) or a feeling of fullness in the abdomen. All these phenomena are specific for peritoneal dialysis and may lead to classic protein energy malnutrition (type I according to Stenvinkel) and hypoalbuminemia [17]. Accepting these constraints, serum albumin still demonstrates a particular strong association with survival. Several studies have demonstrated a negative correlation between the plasma albumin concentration and mortality in patients undergoing maintenance hemodialysis or peritoneal dialysis $[14,19,20]$. Thus, our study makes an important and valuable observation that MNA was able to predict hypoalbuminemia and correlated with albuminemia in the examined group of patients.

Besides the factors discussed above, the results of MNA were correlated with blood lipids (reflecting better nutrition), BMI and time on dialysis.

An intriguing and interesting issue in the peritoneal dialysis population is a problem with obesity [21]. This group of patients is at a risk of weight gain due to the nature of the dialysis technique. Absorption of glucose (100-150 g per day) from dialysate can be a source of up to $800 \mathrm{kcal}$ per day [22]. This phenomenon leads to body fat accumulation along with a rise in concentration of blood lipids [23] and can have further unfavorable metabolic consequences. It is worth noting in the present study that patients classified as malnourished by the MNA scale had lower mean BMI than wellnourished ones, but still above the threshold of underweight. Just $10 \%$ of patients had BMI less then $20 \mathrm{~kg} / \mathrm{m}^{2}$ but $46 \%$ of the group were at least mildly malnourished. In fact, as shown by Leining et al. [24], BMI is related to body fat mass but not to very lean body mass in patients on peritoneal dialysis. This proves again that $\mathrm{BMI}$ is rather a vague indicator of nutritional status in peritoneal dialysis patients. Małgorzewicz et al. [25] observed similar results; in their study, independently of BMI values, $50 \%$ of peritoneal dialysis patients showed signs of malnutrition, $40 \%$ of overweight patients had mild malnutrition, while as many as $60 \%$ of patients in the non-overweight group showed signs of mild malnutrition. Additionally, these authors report an unfavorable adipokine profile in patients with higher BMI. On the other hand, the higher concentration of leptin was associated with loss of lean body mass and muscle wasting. In our observation, BMI in a cohort of peritoneal dialysis patients was not a predictive factor for mortality. As widely discussed, it should be clear that BMI mostly expresses adipose tissue reserve but not lean body weight, which is the valid indicator of nutritional status. The story becomes even more complicated in view of the fact that in peritoneal dialysis patients overhydration can additionally influence BMI. In a paper published by Van Biesen et al. [26] BMI was inversely correlated with tissue hydration. The mentioned tangible variables influencing BMI in peritoneal dialysis patients may lead to conflicting results concerning its impact on survival, which seems to be so evident in hemodialysis cohorts [27].

The main limitations of the study were the relatively small number of participants and its observational design. It can be argued that the measure of worse nutrition could be the consequence of preexisting comorbidities leading to negative outcomes. The study was not designed to answer such a question; nonetheless, according to the existing knowledge on the issue one can speculate that comorbid illnesses may be the link or covariable between malnutrition (type 1 or 2) and morbidity in this population.

In conclusion, this prospective cohort observational study showed that the MNA scale was a valuable, clinically suitable tool for assessment of nutritional status in peritoneal dialysis patients. Being at risk or malnourished when diagnosed by MNA credibly identifies patients at high mortality risk.

\section{References}

1. Chertow GM, Johansen KL, Lew N, Lazarus JM, Lowrie EG. Vintage, nutritional status, and survival in hemodialysis patients. Kidney Int 2000; 57: 1176-81.

2. Rocco MV, Paranandi L, Burrowes JD, et al. Nutritional status in the HEMO Study cohort at baseline. Hemodialysis. Am J Kidney Dis 2002; 39: 245-56.

3. Stenvinkel P, Heimbürger O, Paultre F, et al. Strong association between malnutrition, inflammation, and atherosclerosis in chronic renal failure. Kidney Int 1999; 55: 1899-911.

4. Stenvinkel P, Chung SH, Heimbürger O, Lindholm B. Malnutrition, inflammation, and atherosclerosis in peritoneal dialysis patients. Perit Dial Int 2001; 21 Suppl 3: S157-62.

5. Locatelli F, Fouque D, Heimbürger O, et al. Nutritional status in dialysis patients: a European consensus. Nephrol Dial Transplant 2002; 17: 563-72.

6. Cooper BA, Bartlett LH, Aslani A, Allen BJ, Ibels LS, Pollock CA. Validity of subjective global assessment as a nutritional marker in end-stage renal disease. Am J Kidney Dis 2002; 40: 126-32.

7. Kalantar-Zadeh K, Kopple JD, Block G, Humphreys MH. A malnutrition-inflammation score is correlated with morbidity and mortality in maintenance hemodialysis patients. Am J Kidney Dis 2001; 38: 1251-63.

8. Vellas B, Guigoz Y, Baumgartner M, Garry PJ, Lauque S, Albarede JL. Relationships between nutritional markers and the mini-nutritional assessment in 155 older persons. J Am Geriatr Soc 2000; 48: 1300-9.

9. Vellas B, Guigoz Y, Garry PJ, et al. The Mini Nutritional Assessment (MNA) and its use in grading the nutritional state of elderly patients. Nutrition 1999; 15: 116-22. 
10. Prasad N, Gupta A, Sinha A, et al. Confounding effect of comorbidities and malnutrition on survival of peritoneal dialysis patients. J Ren Nutr 2010; 20: 384-91.

11. Fürstenberg A, Davenport A. Assessment of body composition in peritoneal dialysis patients using bioelectrical impedance and dual-energy X-ray absorptiometry. Am J Nephrol 2011; 33: 150-6.

12. Clinical practice guidelines for nutrition in chronic renal failure. K/DOQI, National Kidney Foundation. Am J Kidney Dis 2000; 35 (6 Suppl 2): S1-140.

13. Adequacy of dialysis and nutrition in continuous peritoneal dialysis: association with clinical outcomes. Canada-USA (CANUSA) Peritoneal Dialysis Study Group. J Am Soc Nephrol 1996; 7: 198-207.

14. Owen WF Jr, Lew NL, Liu Y, Lowrie EG, Lazarus JM. The urea reduction ratio and serum albumin concentration as predictors of mortality in patients undergoing hemodialysis. N Engl J Med 1993; 329: 1001-6.

15. Kaysen GA, Rathore V, Shearer GC, Depner TA. Mechanisms of hypoalbuminemia in hemodialysis patients. Kidney Int 1995; 48: 510-6.

16. Rocco MV, Dwyer JT, Larive B, et al. The effect of dialysis dose and membrane flux on nutritional parameters in hemodialysis patients: results of the HEMO Study. Kidney Int 2004; 65: 2321-34

17. Stenvinkel $P$, Heimbürger $O$, Lindholm $B$, Kaysen GA, Bergström J. Are there two types of malnutrition in chronic renal failure? Evidence for relationships between malnutrition, inflammation and atherosclerosis (MIA syndrome). Nephrol Dial Transplant 2000; 15: 953-60.

18. Ho LC, Wang HH, Chiang CK, Hung KY, Wu KD. Malnutritioninflammation score independently determined cardiovascular and infection risk in peritoneal dialysis patients. Blood Purif 2010; 30: 16-24.

19. Rocco MV, Jordan JR, Burkart JM. The efficacy number as a predictor of morbidity and mortality in peritoneal dialysis patients. J Am Soc Nephrol 1993; 4: 1184-91.

20. Goldwasser P, Mittman N, Antignani A, et al. Predictors of mortality in hemodialysis patients. J Am Soc Nephrol 1993; 3: 1613-22.

21. Bernardo AP, Fonseca I, Rodrigues A, Carvalho MJ, Cabrita A Overweight rather than malnutrition is widely prevalent in peritoneal dialysis patients. Adv Perit Dial 2009; 25: 119-24.

22. Johnson DW. What is the optimal fat mass in peritoneal dialysis patients? Perit Dial Int 2007; 27 Suppl 2: S250-4.

23. Choi SJ, Kim NR, Hong SA, et al. Changes in body fat mass in patients after starting peritoneal dialysis. Perit Dial Int 2011; 31: 67-73.

24. Leinig C, Pecoits-Filho R, Nascimento MM, Gonçalves S, Riella MC, Martins C. Association between body mass index and body fat in chronic kidney disease stages 3 to 5 , hemodialysis, and peritoneal dialysis patients. J Ren Nutr 2008; 18: 424-9.

25. Małgorzewicz S, Aleksandrowicz-Wrona E, Owczarzak A, Debska-Slizień A, Rutkowski B, Łysiak-Szydłowska W. Adipokines and nutritional status for patients on maintenance hemodialysis. J Ren Nutr 2010; 20: 303-8.

26. Van Biesen W, Williams JD, Covic AC, et al. Fluid status in peritoneal dialysis patients: the European Body Composition Monitoring (EuroBCM) study cohort. PLoS One 2011; 6: e17148.

27. Abbott KC, Oliver DK, Hurst FP, Das NP, Gao SW, Perkins RM. Body mass index and peritoneal dialysis: "exceptions to the exception" in reverse epidemiology? Semin Dial 2007; 20: 561-5. 